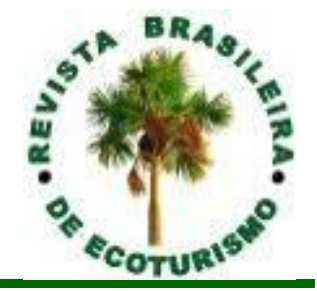

\title{
A Mata Atlântica me ensinou: estudo sobre aprendizado de estudantes com base nas vivências de um projeto de Educação Ambiental em Itu (SP)
}

\section{The Atlantic Forest taught me: reflections on student learning based on the experiences of an Environmental Education project in Itu (SP, Brazil)}

\author{
Kelly De Marchi, Ismail Barra Nova de Melo, \\ Rita de Cássia Lana, Silvio César Moral Marques
}

\begin{abstract}
RESUMO: A Educação Ambiental, formal ou informal, é uma ação importante para ensinar e refletir sobre a importância da natureza, sua diversidade e, principalmente, para provocar mudança de atitude por meio da tomada de consciência e, desta forma, contribuir para a proteção e conservação ambiental. Este estudo buscou analisar o aprendizado de estudantes da Educação Básica que participaram do projeto de Educação Ambiental "Aprendendo com a Mata Atlântica" em 2019 a partir de atividades de vivências na natureza no Centro de Experimentos Florestais SOS Mata Atlântica, no município de Itu (SP). Trata-se de uma pesquisa qualitativa em que a coleta dos dados foi feita com questionário aberto com a participação de 32 escolas e 1256 respostas. A partir da análise dos relatos dos estudantes foi realizado o tratamento de dados e categorização para facilitar o entendimento e utilizado o recurso gráfico nuvem de palavras (NP) na identificação da frequência de palavras em textos volumosos. A maior parte dos estudantes que visitou o Centro de Experimentos é de Itu e região $(90,4 \%)$ e o restante da cidade de São Paulo e entorno (9,6\%). As respostas dadas pelos estudantes do Ensino Fundamental e Médio com maiores percentuais, respectivamente, foram: biodiversidade com 33,1\% e 31,8\%; restauração florestal com 25,6\% e 14,9\%; remanescentes da Mata Atlântica com $10 \%$ e $14,8 \%$ e relação água e floresta com $12,2 \%$ e $11,2 \%$. Estas respostas indicam que a Educação Ambiental realizada em contato com a natureza promove uma tomada de consciência do indivíduo para uma formação da cidadania com vistas à conservação da natureza e prática do Ecoturismo.
\end{abstract}

PALAVRAS-CHAVE: Educação Ambiental; Mata Atlântica; Ecoturismo; Biodiversidade; Ensino Básico. 
ABSTRACT: Environmental Education, whether formal or informal, is an important way to teach and reflect on the importance of nature, its diversity and, especially, to change attitudes through awareness and thus contribute to environmental protection and conservation. This study aims to analyze the Primary and Middle School students learning that participated in the environmental education project "Learning from the Atlantic Forest" in 2019 from the nature experiences activities in Experiments Center Forest SOS Atlantic Forest in the city of Itu (SP, Brasil). This is qualitative research in which data collection was made with open survey with the participation of 32 schools and 1256 answers. From the analysis of the students' reports, data processing and categorization were carried out to facilitate understanding and the word cloud graphic resource (WC) was used to identify the frequency of words in bulky texts. Most of the students who visited the Experiments Center live in Itu and region (90.4\%) and the rest in São Paulo and surroundings (9.6\%). The answers given by elementary and high school students with the highest percentages, respectively, were: biodiversity $33.1 \%$ and $31.8 \%$; forest restoration - $25.6 \%$ and $14.9 \%$; Atlantic Forest remnants $10 \%$ and $14.8 \%$ and relationship between water and forest $-12.2 \%$ and $11.2 \%$. These answers indicate that environmental education held in contact with nature promotes the individual awareness of citizenship formation which takes into account nature conservation and Ecotourism.

KEYWORDS: Environmental Education; Atlantic Forest; Ecotourism; Biodiversity; Basic Education.

\section{Introdução}

A temática da conservação ambiental deve ser inserida como parte do cotidiano de toda a humanidade para a manutenção da qualidade de vida no Planeta (VENTURIN et al., 2013).

Um alerta mundial sobre os problemas ambientais veio com a publicação, em 1962, do livro "A Primavera Silenciosa", de Rachel Carson (CARSON, 1969), que denunciava os efeitos danosos de ações humanas sobre o meio ambiente como os pesticidas. Este fato foi considerado 0 propulsor da consciência ecológica mundial e o marco inicial da Educação Ambiental (EA) que conhecemos hoje, mesmo tendo o termo EA surgido pela primeira vez em 1965, em uma Conferência em Educação na Universidade de Kelle, no Reino Unido (DIAS, 2013).

De acordo com Layrarques e Lima (2011) existem muitos caminhos para que a Educação Ambiental possa ser realizada dependendo das circunstâncias com escolhas específicas, já que "[...] uns crêem ser determinante 0 desenvolvimento da afetividade e sensibilidade na relação com a natureza, outros entendem que é fundamental conhecer os princípios e fundamentos ecológicos que organizam a vida" (LAYRARGUES; LIMA, 2011, p.28).

De forma a unir o domínio afetivo e cognitivo, as experiências de contato com áreas naturais contribuem com mudanças de comportamento nas pessoas e se estabelecem em importantes instrumentos educativos para iniciativas de proteção e conservação ambiental sem os quais estariam destinadas ao insucesso (WELLS; BRANDON, 1992).

Nesse sentido e em busca de estabelecer um uma nova relação homem-natureza, o processo educativo torna-se essencial para atingir esse propósito, com os princípios e valores éticos estabelecidos, que não seja sinônimo de autodestruição, mas de enxergar essa relação prioritária para a existência humana. (REIGOTA, 1995). Jeff (2001) também reforça que os 
problemas ambientais são resultados de uma grande crise civilizatória em que o ser humano relaciona a natureza como fornecedora de recursos e a partir disso entende que o ponto de partida ao se discutir as questões ambientais deve ter, obrigatoriamente, a revisão do posicionamento humano no mundo.

Segundo Reigota (2002) a escola e a floresta têm muito a nos ensinar, sendo necessário relacionar os saberes com a capacidade de entendimento, passando pelo processo de perceber não só o outro, mas se perceber como parte do todo e que tudo que está ao nosso redor está interligado dentro do ecossistema.

No momento em que estudantes aprendem algo significativo que não conheciam, eles não aprenderam somente algo novo, mas através desse algo novo, eles alteraram, de algum modo, todo seu sistema cognitivo. Em nós, humanos, cada diferente momento de interação-integração é alterado qualitativamente por meio de cada ato pedagógico de aprendizagem, com trocas e a partir do que se apropria, é criado seu próprio saber. Na Educação Ambiental, quando o objetivo é criar uma nova consciência a respeito da vida, natureza, ambiente e da nossa corresponsabilidade, é necessário o saber de todos. Aprender é integrar novas informações, novas sensibilidades e novos saberes e todo saber é uma partilha. (SORRENTINO et al., 2013).

A Educação Ambiental, promovida em qualquer espaço, busca por melhorias no meio ambiente e uma aproximação do homem com a natureza, não apenas do ponto de vista físico, mas conceitual, desta forma, promovendo a valoração da natureza em todas as suas atitudes, quer dizer, formação para a cidadania e, consequentemente, para as atividades do Ecoturismo. O Ecoturismo entendido com os vínculos com a educação, conservação e sustentabilidade e que compreende as atividades turísticas com vistas a interação sustentável entre o homem e a natureza (COELHO, CAMARGO, 2021). Para Padua (1997, p.35) "[...] num processo dinâmico, as condições externas podem influenciar a atitude das pessoas com relação ao meio ambiente. Daí o grande valor de expor as pessoas a um ambiente natural, onde existe a oportunidade de aprendizado e sensibilização".

Esta pesquisa se justifica para avaliar a contribuição do projeto da Fundação SOS Mata Atlântica junto aos estudantes do Ensino Básico em relação a importância e características do bioma Mata Atlântica por meio da Educação Ambiental que vem sendo realizada no local.

O objetivo desta pesquisa é interpretar os aprendizados de estudantes do ensino básico no projeto Aprendendo com a Mata Atlântica.

\section{O projeto Aprendendo com a Mata Atlântica}

Criado em 2010 pela Fundação SOS Mata Atlântica, o projeto de Educação Ambiental é realizado no Centro de Experimentos Florestais SOS Mata Atlântica - Grupo HEINEKEN no Brasil (CEF), localizado em Itu-SP, em uma antiga fazenda produtora de café e gado (Figura 1). Com um total de 524 hectares e cerca $80 \%$ da fazenda desmatada, iniciou-se o processo de plantio de mudas com a prática da restauração florestal, que visa inserir a partir de avaliações técnicas, espécies florestais nativas de acordo com a diversidade regional. O objetivo também foi de estruturar o espaço não só para atuação com restauração florestal, mas também uma área para atividades relacionadas a conservação da biodiversidade, transformando este espaço 
em um laboratório a céu aberto com a oportunidade de ações experimentais e demonstrativas, capacitação técnica, pesquisa, Educação Ambiental, sensibilização e mobilização (FUNDAÇÃO SOS MATA ATLÂNTICA, 2019).

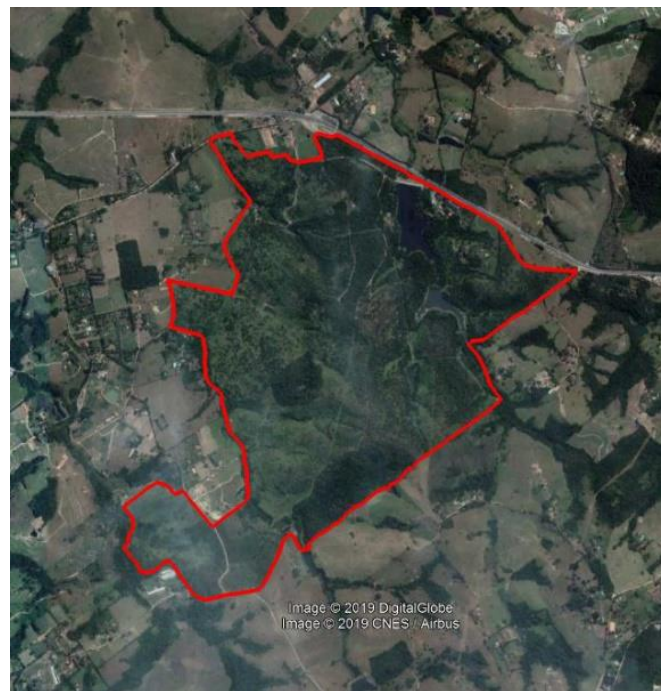

Figura 1: Delimitação do Centro de Experimentos Florestais e os fragmentos Fonte: Google Earth (2021)

Figure 1: Delimitation of the Forestry Experiments Center and the fragments

Source: Google Earth (2021)

Além da recepção de grupos, o projeto tem realizado formação de educadores com temas como "Elaboração de Projetos na Escola", "Aprendizado com Foco", "Formação de Monitores". As atividades de Educação Ambiental são realizadas em ambientes como o viveiro de mudas nativas, jardim sensorial, trilha interpretativa e centro de interpretação. Com essa iniciativa, o projeto de Educação Ambiental já alcançou cerca de 50 mil participantes para atividades de vivências na natureza, em sua maioria, professores e estudantes, vindos de 35 cidades do estado de São Paulo (FUNDAÇÃO SOS MATA ATLÂNTICA, 2019).

\section{Material e Métodos}

\section{Delineamento da pesquisa}

Essa é uma pesquisa de caráter qualitativo e delineamento longitudinal realizada através de questionário aberto (KUSS et. al., 2015).

\section{Sujeito da Pesquisa}

Participaram da pesquisa estudantes dos ensinos fundamental II e médio, de diferentes instituições (municipais, estaduais, federais e particulares) localizadas nas regiões de Campinas, Sorocaba, Jundiaí e Grande São Paulo.

\section{Coleta de Dados}

Os dados foram coletados entre os meses de maio a dezembro de 2019 com um total de 1.256 respostas. Com a intenção de identificar o aprendizado dos estudantes a partir das visitas monitoradas e das atividades 
de vivência na natureza no CEF, foi utilizada a pergunta aberta ao final da visita "O que aprendi e não sabia?", feita de forma verbal pelos educadores e respondida em até 15 minutos com escrita livre pelos estudantes.

\section{Análise de Dados}

Com a premissa de assegurar a confiabilidade da pesquisa com erro amostral não superior a 5\%, foi realizado o cálculo de amostra aleatória simples aplicada às Ciências Sociais (BARBETTA, 2002). Com o universo de 2.624 estudantes do ensino fundamental II e médio que participaram do projeto, uma amostra confiável para essa pesquisa seria de 336 questionários, no entanto, foram analisados 1.256 questionários.

Os questionários foram transcritos e tabulados em planilha de Excel. Por se tratar de um estudo de caso, foi utilizada a análise de conteúdo com categorização a posterior, ou seja, foram criadas categorias após a análise dos dados (MINAYO, 1992), sendo esses interpretados de acordo com a frequência semântica e dos assuntos abordados no roteiro de atividades do Projeto e os relatos que se enquadravam em mais de uma categoria foram divididos em duas ou mais categorias. Para Moraes (1999), a análise de conteúdo ajuda a reinterpretar as mensagens que vão além de uma leitura comum, sendo usado para descrever o conteúdo de toda classe de texto, sendo elas qualitativas ou quantitativas.

A partir da categorização dos resultados, foi utilizada a ferramenta gratuita World Clouds (www.wordlclouds.com) para apresentar a frequência de palavras e, posteriormente, gerar a Nuvem de Palavras (NP) para cada categoria. Considerou-se imprescindível a revisão dos arquivos, com a uniformização de siglas, a correção de erros de digitação e ortográficos, além da padronização de variações no singular e no plural que possuem o mesmo significado. Após readequação do texto relativo a cada questão, foram geradas as Nuvens de Palavras para cada categoria. A última configuração feita foi em relação ao número máximo de palavras por nuvem. Com o objetivo de concentrar apenas as palavras mais importantes, configurou-se a nuvem para ter no máximo 10 palavras.

\section{Resultados e Discussão}

Por meio da Figura 2 verifica-se a distribuição geográfica dos participantes da pesquisa. Essas instituições estão localizadas em 12 municípios do estado de São Paulo, incluindo a capital. Parcela destas instituições $(40,6 \%)$ são oriundas de Itu-SP onde está sediado o projeto, mas, a maioria $(59,4 \%)$ é proveniente de municípios do seu entorno.

A distribuição geográfica dos visitantes desta pesquisa, Figura 2, é similar ao apontado por Fernantes et al. (2017) no estudo em que avaliou os resultados obtidos com a implantação do Programa Criança ecológica na Floresta Estadual de Bebedouro-SP. No Programa, a visitação se deu com maior frequência por estudantes residentes nos municípios próximos a Floresta Estadual, Bebedouro, enquanto nesta pesquisa os visitantes também vieram dos municípios do entorno de Itu, local onde está situado o projeto. 


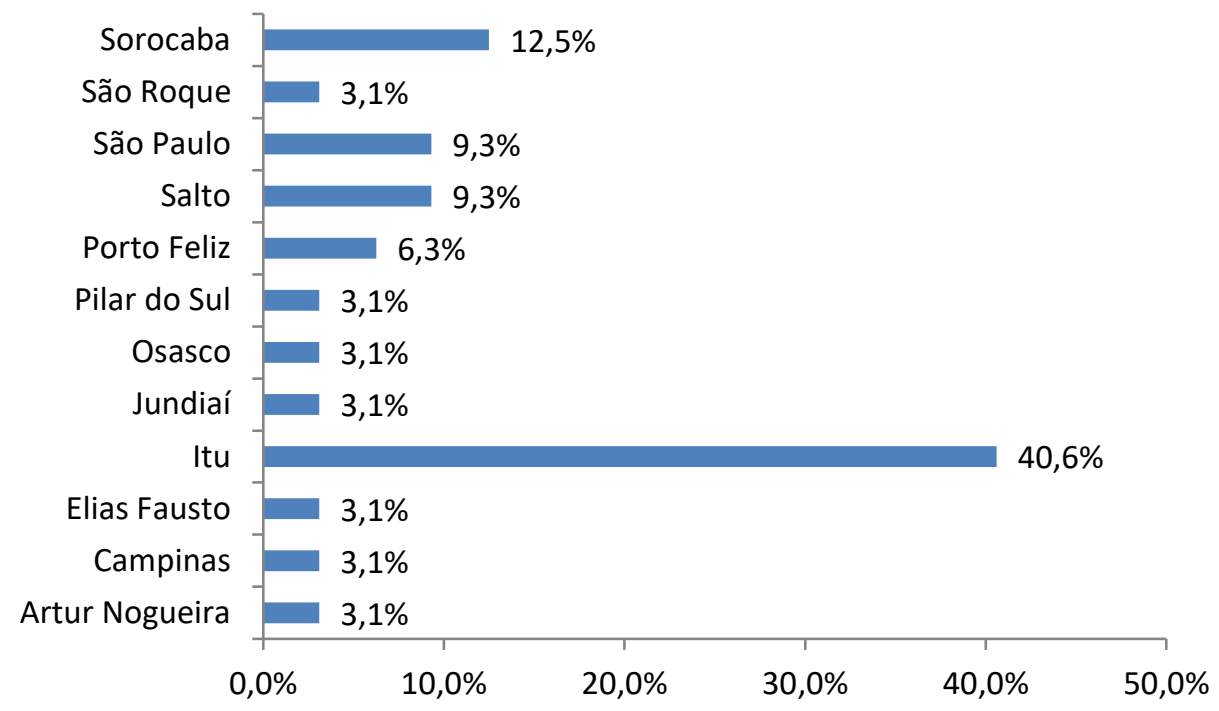

Figura 2: Distribuição geográfica das instituições participantes da pesquisa Figure 2: Geographical distribution of institutions participating in the research

A maioria das respostas (59\%) foi de estudantes do ensino médio, com destaque para os $1^{\circ}$ e $2^{\circ}$ anos (Tabela 1). Esta situação pode ser considerada esperada, visto que a maior parte dos estudantes foi composta por esse nível de ensino, 743 estudantes no total, enquanto o total de estudantes do Ensino Fundamental foi de 513 alunos.

Tabela 1: Distribuição das etapas e séries dos estudantes que participaram da pesquisa.

Table 1: Distribution of educational levels of students who participated in the research.

\begin{tabular}{cccc}
\hline \multirow{2}{*}{ Ensino } & \multirow{2}{*}{ Série } & \multicolumn{2}{c}{ Participantes } \\
& & N & \% \\
\hline 5o ano & 24 & 1,91 \\
& 6o ano & 95 & 7,56 \\
& 70 ano & 239 & 19,03 \\
& 80 ano & 102 & 8,12 \\
& 9o ano & 53 & 4,22 \\
& TOTAL & $\mathbf{5 1 3}$ & $\mathbf{4 0 , 8 4}$ \\
\hline \multirow{3}{*}{$:$} & 1o ano & 325 & 25,88 \\
& 2o ano & 337 & 26,83 \\
& 3o ano & 81 & 6,45 \\
& TOTAL & $\mathbf{7 4 3}$ & $\mathbf{5 9 , 1 6}$ \\
\hline
\end{tabular}

Legenda: $\mathrm{N}=$ Número de participantes; \% = Porcentagem.

Para melhor análise dos questionários, fez-se necessário agrupá-los em categorias, sendo a categoria biodiversidade a que mais se destacou tanto pelos estudantes do ensino fundamental (33\%) quanto do ensino médio (31\%) (Tabela 2). 
Tabela 2. Distribuição dos relatos dos estudantes por categoria.

Table 2. Distribution of student reports by category.

\begin{tabular}{ccccccc}
\hline \multirow{2}{*}{ Categoria } & \multicolumn{2}{c}{ Ensino Fundamental } & \multicolumn{2}{c}{ Ensino Médio } & \multicolumn{2}{c}{ Total } \\
& Número & $\mathbf{\%}$ & Número & $\mathbf{\%}$ & Número & \% \\
\hline Biodiversidade & 229 & 33,1 & 306 & 30,9 & 535 & 31,8 \\
Restauração Florestal & 177 & 25,6 & 74 & 7,5 & 251 & 14,9 \\
Remanescentes da Mata Atlântica & 69 & 10 & 179 & 18,1 & 248 & 14,8 \\
Relação água e floresta & 84 & 12,2 & 105 & 10,6 & 189 & 11,2 \\
Observações & 69 & 10 & 163 & 16,5 & 232 & 13,8 \\
Importância do bioma & 29 & 4,2 & 66 & 6,7 & 95 & 5,7 \\
Morador da Mata Atlântica & 33 & 4,8 & 73 & 7,4 & 106 & 6,3 \\
Lei da Mata Atlântica & 1 & 0,1 & 24 & 2,4 & 25 & 1,5 \\
TOTAL & $\mathbf{6 9 1}$ & $\mathbf{1 0 0}$ & $\mathbf{9 9 0}$ & $\mathbf{1 0 0}$ & $\mathbf{1 6 8 1}$ & $\mathbf{1 0 0 , 0}$ \\
\hline
\end{tabular}

Legenda: \% = Portentagem.

Para interpretar os aprendizados de estudantes do ensino básico no projeto "Aprendendo com a Mata Atlântica" utilizamos as frequências de palavras referentes às categorias, Tabela 3 , seguidas das Nuvens de Palavras, Figuras 3 a 9.

Tabela 3: Frequência de palavras referentes as categorias Água x Floresta, Restauração Florestal e Biodiversidade.

Table 3: Frequency of words referring to the categories Water x Forest, Forest Restoration

\begin{tabular}{cccccc}
\hline \multicolumn{2}{c}{ Água x Floresta } & \multicolumn{2}{c}{ Restauração Florestal } & \multicolumn{2}{c}{ Biodiversidade } \\
Frequência & Palavra & Frequência & Palavra & Frequência & Palavra \\
\hline 98 & atlântica & 169 & restauração & 911 & atlântica \\
70 & água & 161 & reflorestamento & 276 & mata \\
67 & mata & 140 & atlântica & 198 & árvores \\
53 & restauração & 94 & diferença & 95 & plantas \\
39 & reflorestamento & 58 & mata & 78 & espécies \\
32 & nascentes & 40 & árvores & 63 & sementes \\
28 & árvores & 29 & plantas & 58 & animais \\
24 & floresta & 25 & floresta & 51 & jequitiba-rosa \\
24 & freático & 15 & restaurar & 42 & insetos \\
24 & lençol & 14 & processo & 28 & floresta \\
\hline
\end{tabular}

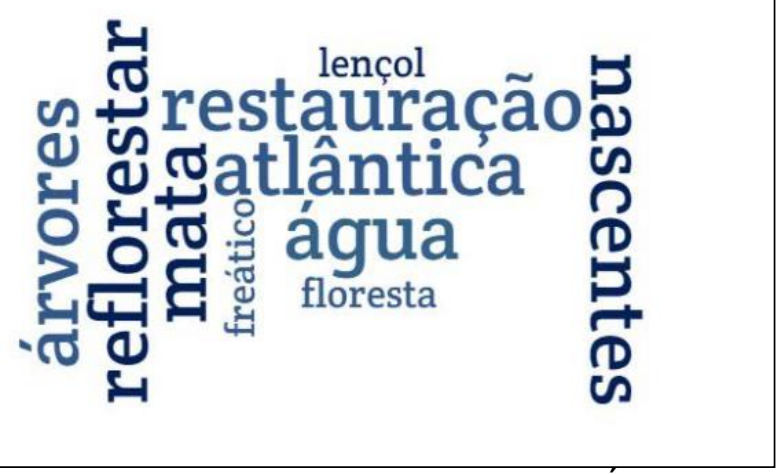

Figura 3: Nuvem de Palavra - Categoria Relação Água e Floresta.

Figure 3: Word Cloud - Relation Water and Forest. 
A relação entre água e floresta se destacou dentre os relatos dos estudantes, principalmente com a demonstração da maquete da mata ciliar e da visita ao lago da fazenda, traduzindo assim a importância da cobertura vegetal em APP's (Área de Preservação Permanente), com relatos como:

"Aprendi a importância da mata para a regulação do nível dos rios", estudante do ensino médio.

"Eu aprendi sobre o lençol freático, foi muito legal. E que as matas têm que ficar perto dos rios porque se não absorve", estudante do ensino fundamental.

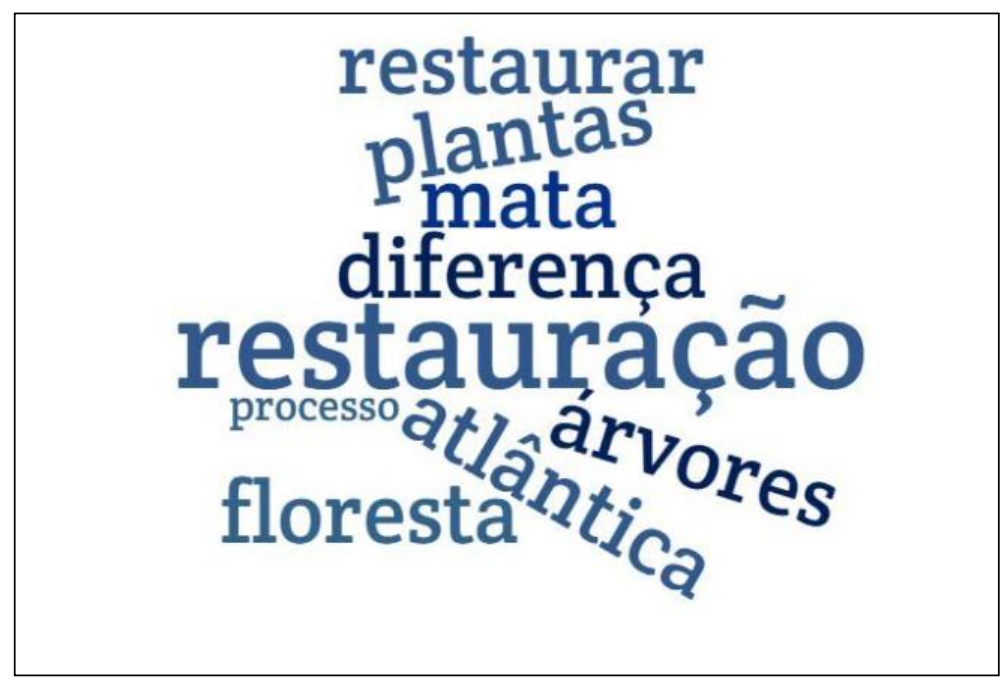

Figura 4: Nuvem de Palavra - Categoria Restauração Florestal.

Figure 4: Word Cloud - Forest Restoration.

Estes relatos de aprendizados vão ao encontro de uma Educação Ambiental voltada para o enfrentamento da questão ambiental que tem como fim a internalização da dimensão ambiental no sistema de ensino (LAYRARQUES, 2006).

Conhecer um viveiro de mudas nativas e todo o processo de produção de mudas, da chegada das sementes até o plantio, proporcionou aos estudantes alguns aprendizados, como a importância do plantio de espécies nativas e basicamente o que envolve a ciência da restauração florestal, que visa formar uma floresta com seus serviços ecossistêmicos.

"Eu não sabia que ao restaurar um bioma, além de você melhorar a qualidade do ar, você ajuda os animais, trazendo o viver deles e ajudando a sua espécie", estudante do ensino fundamental.

"A diferença entre reflorestamento e restauração. Os dois são sobre plantar nas áreas desmatadas, porém a restauração ocorre com espécies nativas para não afetar o bioma", estudante do ensino médio. 
"É mais fácil cuidarmos do que temos que começar tudo novamente, demora para começar novamente", estudante ensino fundamental.

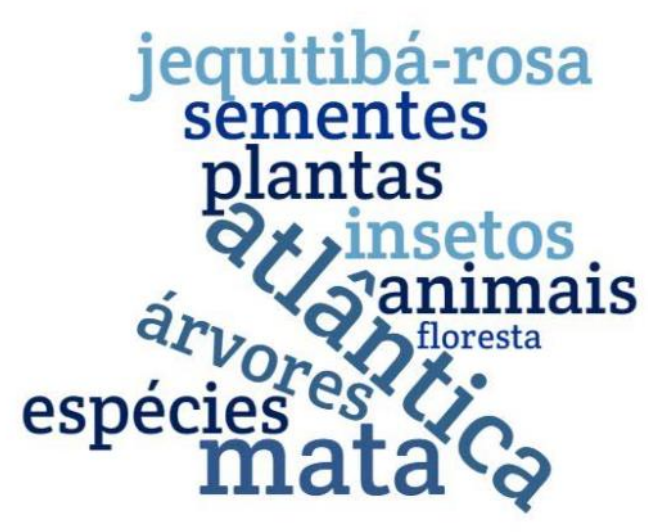

Figura 5: Nuvem de Palavra - Categoria Biodiversidade.

Figure 5: Word Cloud - Biodiversity.

As falas dos estudantes a partir desta experiência estão alinhadas com os pressupostos defendidos por Mendonça (2017, p.16) no qual o conhecimento deve ser complementado pela experiência. "Há muitas pesquisas bem fundamentadas que afirmam que, para melhores resultados na aprendizagem, a experiência aparece como tão importante quanto 0 conhecimento".

Dentre os aprendizados sobre biodiversidade, a categoria com mais relatos, a vivência na trilha trouxe algumas experiências e reflexões, como alguns destaques:

"Aprendi que dentro da mata é muito diferente, lá dentro tem muito barro, muitas árvores e muitos animais e insetos", estudante do ensino fundamental.

"Aprendi sobre a decomposição porque eu não entendia muito mas agora eu sei e também sobre como é importante todos os animais até como insetos é muito importante para o nosso planeta terra", estudante do ensino fundamental.

"Não conhecia o som do tucano, ouvi hoje pela primeira vez", estudante do ensino médio.

"Eu gostei muito da parte que vi os saguis, nunca tive um contato assim. Porque não é a mesma coisa do que em zoologia”, estudante do ensino médio.

Estes relatos de aprendizados estão inseridos numa abordagem de vivência sensíveis com espaços naturais, pois, as vivências consideram "[...] 0 visitante por inteiro, acolhe suas percepções e sentimentos e busca orientá-lo de forma a perceber aspectos muito sutis da mata" (MENDONÇA, 2017, p. 15). 
Tabela 4: Frequência de palavras referentes às categorias Lei da Mata Atlântica, Morador na Mata Atlântica, Observações e Remanescentes.

Table 4: Frequency of words referring to the Atlantic Forest Law, Atlantic Forest Resident, Observations and Remnants categories.

\begin{tabular}{cccccccc}
\hline \multicolumn{2}{c}{ Lei da Mata Atlâtica } & \multicolumn{2}{c}{ Morador da Mata Atlântica } & \multicolumn{2}{c}{ Observações } & \multicolumn{2}{c}{ Remanescentes } \\
Frequência & Palavra & Frequência & Palavra & Frequência & Palavra & Frequência & Palavra \\
\hline 60 & atlântica & 183 & atlântica & 174 & atlântica & 728 & atlântica \\
30 & mata & 62 & mata & 68 & mata & 312 & mata \\
23 & lei & 38 & moramos & 66 & árvores & 137 & desmatamento \\
16 & proteção & 17 & vivem & 27 & plantas & 54 & restou \\
11 & único & 13 & humanos & 18 & morrem & 53 & bioma \\
4 & bioma & 6 & animais & 18 & sementes & 28 & apenas \\
3 & especificamente & 4 & somos & 15 & clareira & 24 & Brasil \\
3 & federal & 3 & estamos & 13 & floresta & 24 & existe \\
3 & preservar & 3 & gente & 12 & smatamen & 20 & sobrou \\
3 & protege & 2 & bioma & 12 & dispersão & 20 & áreas \\
\hline
\end{tabular}

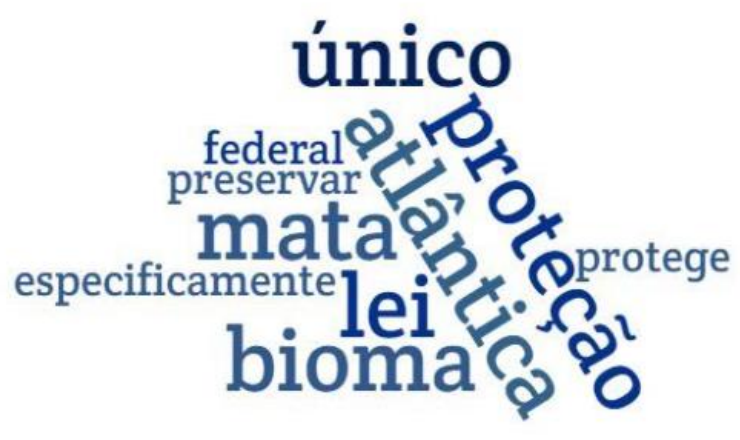

Figura 6: Nuvem de Palavra - Categoria Lei da Mata Atlântica.

Figure 6: Word Cloud - Atlantic Forest Law.

Apesar da categoria sobre Lei da Mata Atlântica, com relatos em sua maioria do ensino médio, ser a menos mencionada, trouxe pontos importantes como:

"Aprendi que a Mata Atlântica é o único bioma brasileiro com lei específica de proteção", estudante do ensino médio.

"Não sabia que tinha multa por tirar árvores da Mata Atlântica", estudante do ensino fundamental. 


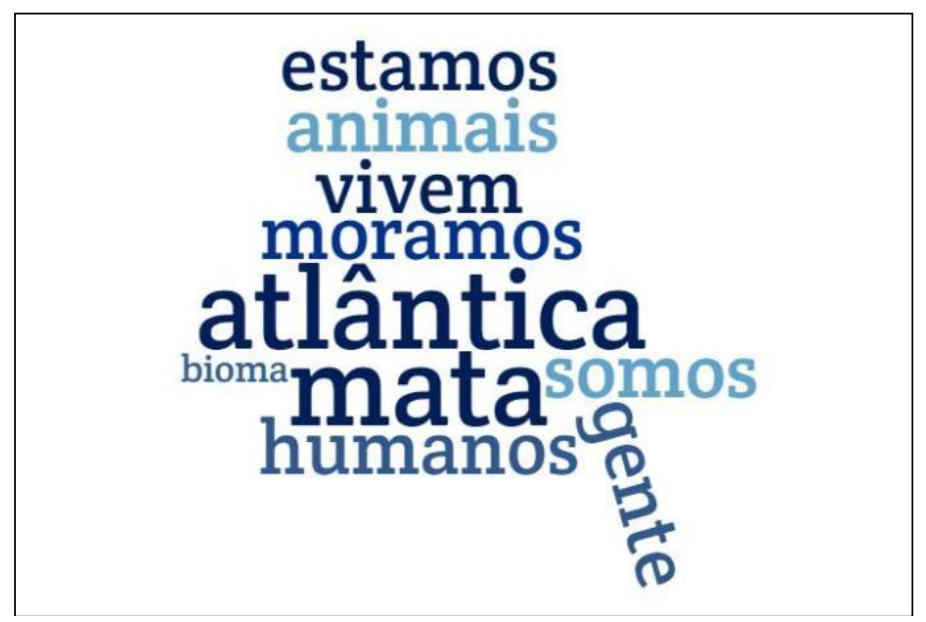

Figura 7: Nuvem de Palavra - Categoria Moro/Pertenço a Mata Atlântica Figure 7: Word Cloud - Reside/Belong in the Atlantic Forest

A descoberta que moram na Mata Atlântica trouxe uma sensação de pertencimento, destacada por relatos como:

"Eu não sabia que vivia em uma área de Mata Atlântica e transição do Cerrado e que o ser humano também é considerado parte do ambiente", estudante do ensino médio.

"Eu aprendi que nós moramos na mata atlântica e precisamos dela para nossa sobrevivência", estudante do ensino fundamental, estudante do ensino fundamental.

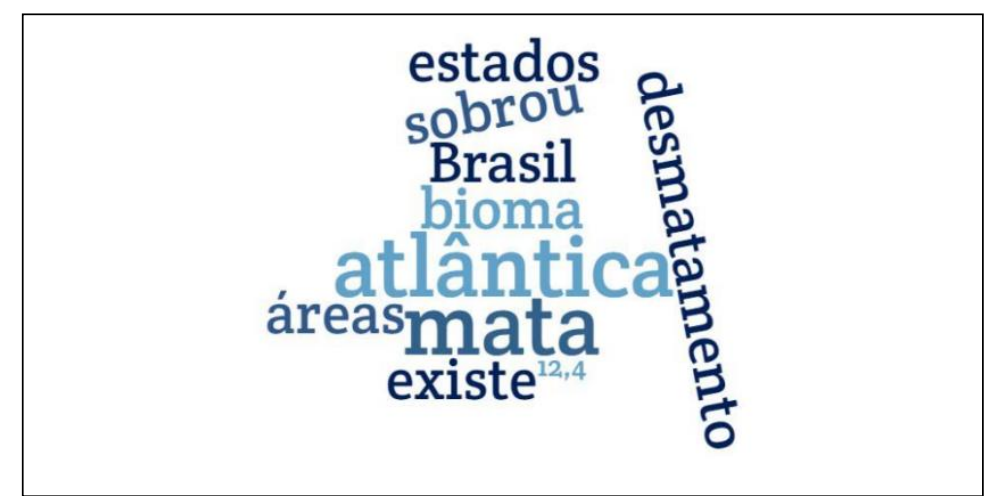

Figura 8: Nuvem de Palavra - Categoria Remanescentes da Mata Atlântica.

Figure 8: Word Cloud - Remnants of the Atlantic Forest.

Estas sensações de descobertas relatadas pelos estudantes, de pertencimento e de inserção no bioma Mata Atlântica se inserem quando estamos "[...] imersos em uma área natural e buscamos equilibrar os pensamentos e as sensações, percebemos como podemos nos dar conta de uma infinidade de fenômenos que acontecem simultaneamente" (MENDONÇA, 2017, p. 21).

A partir da visualização do mapa do Brasil, com destaque à área original de Mata Atlântica e o que resta hoje, os relatos trouxeram perplexidade quando é apresentado que restam somente $12,4 \%$ do bioma, como: 
"Eu não sabia que a Mata Atlântica podia ser tão grande e ao mesmo tempo tão pequena", estudante do ensino fundamental.

"Eu aprendi que 12,4\% é o que restou da Mata Atlântica, e que existe muita área desmatada”, estudante ensino médio.

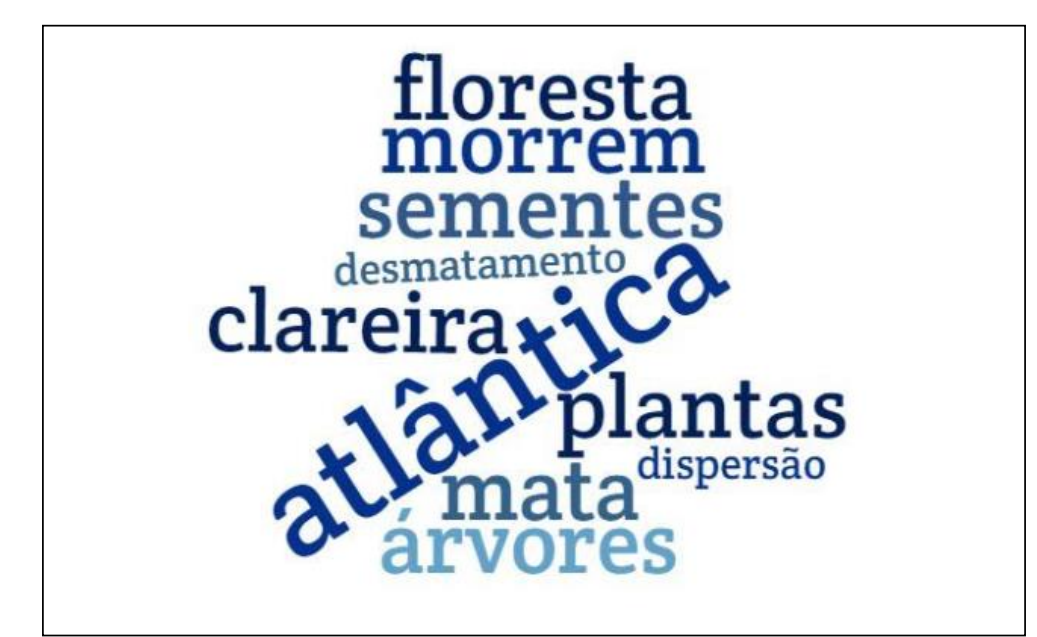

Figura 9: Nuvem de Palavra - Categoria Observações/Curiosidades

Figure 9: Word Cloud - Notes / Trivia

A Educação Ambiental por si só não resolverá os mais complexos problemas ambientais, mas poderá contribuir de modo decisivo para isso, a partir da formação de seus cidadãos, que passam a ter conhecimento e consciência das problemáticas globais e, com isso, passam a agir diante de suas realidades, promovendo mudanças, ainda que não imediatas e visíveis, mas, também não sendo sem efeitos concretos (REIGOTA, 1998).

Alguns relatos que não se enquadravam em nenhuma das categorias foram incluídos em observações/curiosidades feitos pelos estudantes, como:

"Aprendi que o termo "mais evoluído" é incorreto, quando se trata de falar do ser humano e os macacos", estudante do ensino fundamental.

"Uma exploração muito enriquecedora e cativante pois aprendemos sobre a atual situação florestal no Brasil e como isso nos afetará no futuro. Também como podemos mudar a realidade levemente desencorajadora do mundo", estudante do ensino médio.

"Eu aprendi muita coisa de natureza aqui no SOS. Aprendi a não ter medo de lagarto", estudante do ensino fundamental.

"Eu aprendi que as manchas cinzas nas árvores é sinal de ar de boa qualidade" estudante do ensino fundamental. 


\begin{abstract}
"Aprendi que a floresta não é só arvores e sem vidas além das árvores cada um vive do seu jeito, e que podemos ajudar mesmo com pouco", estudante do ensino médio.

"Seiva, ela é gosmenta meia amarela e parece mel, a primeira vez que eu vi ela pensei que era o mel que a árvore cospia para os pássaros comerem", estudante ensino fundamental.
\end{abstract}

As evidências trazidas pelas nuvens de palavras a partir dos relatos dos estudantes valida a importância das atividades na natureza realizadas pelo projeto Aprendendo com a Mata Atlântica, com vistas a fortalecer, não somente os aprendizados conceituais, mas também aqueles a partir da observação e da descoberta individual.

A categoria biodiversidade teve destaque tanto no ensino fundamental como no ensino médio, podendo ser explicada devido a sermos seres biofílicos, que é a afetividade emocional inata dos seres humanos para com as demais espécies da terra (WILSON, 1984).

Outros destaques foram as descobertas sobre o quanto restou de Mata Atlântica e a importância da restauração florestal, que muito se deu pela experiência de ver o antes e o depois de uma floresta restaurada e, assim, perceber que é possível recuperar a natureza.

O que podemos gerar e fazer com o bom uso de nossos aprendizados e de nossos conhecimentos representa nada menos do que a construção de um mundo de solidariedade, de justiça, de igualdade (SORRENTINO et al., 2013, p.39).

\title{
Considerações Finais
}

A partir dos resultados alcançados pode-se correlacionar que o Centro de Experimentos Florestais "SOS Mata Atlântica" vem cumprindo com os seus objetivos, dentre outros, de ser um espaço para a prática da Educação Ambiental em meio a natureza com cerca de 50 mil visitantes até o momento, com atendimento de diferentes níveis de estudantes da região de Itu-SP, principalmente de escolas públicas.

Os aprendizados dos estudantes, descritos por meio dos relatos, reforçam que o ensino e a aprendizagem não podem ficar restritos a quatro paredes da sala de aula. Em outras palavras, os conhecimentos e a experiência em meio à natureza são complementares, daí a importância das visitas com as atividades de sensibilização em meio ao bioma Mata Atlântica.

A Educação Ambiental realizada por meio de diferentes atividades: a visualização da maquete da mata ciliar, a visita ao lago da fazenda, a visita ao viveiro de mudas, a experiência da trilha, a discussão da Lei da Mata Atlântica, e a leitura do mapa do Brasil com a demonstração dos fragmentos restantes da vegetação original, produziram as mais diferentes experiências e percepções nas visões dos estudantes com associações importantes, como na relação entre água e floresta, a importância dada à mata ciliar nos relatos. $\mathrm{Na}$ categoria restauração, a associação de que a preservação e conservação são mais importantes do que a restauração. Já na categoria Lei da Mata 
Atlântica a associação ficou por conta da importância da legislação para a manutenção do bioma.

A Educação Ambiental, formal ou informal, dentro ou fora da sala de aula, em ambiente urbano ou em meio à natureza ainda continua sendo uma opção para proporcionar reflexões importantes para se construir outra realidade social com mais equidade entre as pessoas e, consequentemente, com mais harmonia com a natureza.

\section{Referências}

BARDIN, L. Análise de conteúdo. São Paulo: Edições 70, 2011, 229 p.

BRUHNS, H. T. Esporte e natureza: o aprendizado da experimentação. In: SERRANO, C. (org). A educação pelas pedras: Ecoturismo e Educação Ambiental. São Paulo: Chronos, p.25-46., 2000.

BRASIL, Constituição (1988). Constituição da República Federativa do Brasil de $1988 . \quad$ Disponível em: $<$ http://www.planalto.gov.br/ccivil 03/constituicao/ConstituicaoCompilado.html >. Acesso em: 8 fev. 2021.

BRASIL. DECRETO № 4.281, DE 25 DE JUNHO DE 2002. Disponível em: $<$ http://www.planalto.gov.br/ccivil 03/decreto/2002/d4281.html>. Acesso em: 15 de fevereiro de 2021.

BRASIL. Decreto $\mathrm{n}^{\circ} \mathbf{7 3 . 0 3 0}$, de 30 de Outubro de 1973. 1973. Disponível em: <https://www2.camara.leg.br/legin/fed/decret/1970-1979/decreto-7303030-outubro-1973-421650-publicacaooriginal-1-pe.html>. Acesso em: 15 fev. 2021.

BRASIL. Lei da Mata Atlântica. 2006. Disponível em: $<$ https://legislacao.presidencia.gov.br/atos/?tipo=LEl\&numero=11428\&ano=20 06\&ato=1e8cXSq5kMRpWT08e $>$. Acesso em: 15 fev. 2021.

CARSON, Rachel. Primavera Silenciosa. São Paulo: Editora Melhoramentos, 1969

CARVALHO, I. C. M. Em direção ao mundo da vida: interdisciplinaridade e Educação Ambiental / Conceitos para se fazer Educação Ambiental / IPÊ Instituto de Pesquisas Ecológicas, Brasília-DF, 1998.

COELHO, S. C .A; CAMARGO, C. F de. A llha Canela, Palmas (TO): Uma análise socioeconômicados visitantes e do Ecoturismo. Revista Brasileira de Ecoturismo, São Paulo, v 14, n.2, mai-jul2021, pp. 145-159.

DEAN, Warren. A ferro e fogo: a história e a devastação da Mata Atlântica brasileira. 1. ed. São Paulo: Cia. das Letras, 2004. 484 p.

DIAS, Genebaldo F. Educação Ambiental: princípios e práticas. 9a. ed. São Paulo: Gaia, 2013.

FENNELL, D. Ecoturismo: Uma Introdução. São Paulo: Contexto, 2002.

FERNANDES, A.N.P. et al. Avaliação dos resultados obtidos com a implantação do Programa Criança Ecológica na Floresta Estadual de Bebedouro (SP). Revista Brasileira de Educação Ambiental, São Paulo, v. 12, n.1: 12-23, 2017. 
FUNDAÇÃO SOS MATA ATLÂNTICA. Relatório do Atlas da Mata Atlântica. 2020. Disponível em: <https://www.sosma.org.br/wpcontent/uploads/2020/11/Relat\%C3\%B3rio-Anual-2019-SOS-Mata-

Atl\%C3\%A2ntica.pdf>.Acesso em: 15 de fevereiro de 2021.

KNUPP, M. E. C. G. Fundamentos do Turismo. Curitiba: InterSaberes, 2015. KUSS, A. V., CARLAN, F. A., BEHLING, G. M., GIL, R. L. Possibilidades metodológicas para a pesquisa em Educação Ambiental. Pelotas: Santa Cruz, 2015.

LAYRARGUES, P.P. Muito além da natureza: Educação Ambiental e reprodução social. In: LOUREIRO, C.F.B; LAYRARGUES, P.P.; CASTRO, R. C. (Orgs). Pensamento complexo, dialética e Educação Ambiental. São Paulo: Cortez, 2006).

LAYRARGUES, P.P.; LIMA, G. Mapeando as macro-tendências políticopedagógicas da Educação Ambiental contemporânea no Brasil. Anais do VI Encontro "Pesquisa em Educação Ambiental" A Pesquisa em Educação Ambiental e a Pós-Graduação no Brasil., [S. I.], p. 1-15, 2011.

LOHMANN, G.; PANOSSO NETTO, A. Teoria do turismo: Conceitos, modelos e sistemas. São Paulo: Aleph, 2008.

LOUREIRO, C.F.B.; LAYRARGUES, P.P. Ecologia política, justiça e Educação Ambiental crítica: perspectivas de aliança contra-hegemônica. Disponível em: <https://www.scielo.br/j/tes/a/8VPJg4SGvJLhcK3xcrrnHRF/ ?lang=pt>. Acesso em: 15 de fevereiro de 2021

MARQUES, M.C.M.; GRELLE, C.E.V. The Atlantic Forest: history, biodiversity, threats and opportunities of the mega-diverse forest. 1a ed. Cham: Springer, 2021.

McKERCHER, B. Turismo de natureza: Planejamento e sustentabilidade. São Paulo, SP: Contexto, 2002.

MENDONÇA, R. Atividades em áreas naturais [livro eletrônico]. 2a. ed. São Paulo: Ecofuturo, 2017.

MINAYO, M. C. S. O desafio do conhecimento: pesquisa qualitativa em saúde. 2.ed., São Paulo - Rio de Janeiro, Hucitec-Abrasco, 1992.

ONU. United Nations Decade on Ecosystem Restoration (2021-2030) Resolution adopted by the General Assembly. Disponivel em: $<$ https://undocs.org/A/RES/73/284 >. Acesso em: 15 fev. 202.

PADUA, S. M. . Uma pesquisa em Educação Ambiental: a conservação do mico-leão-preto (Leontopithecus chrysopygus). In: VALLADARES- PADUA, C.; BODMER, R.; CULLEN Jr., L. (orgs.). Manejo e Conservação de Vida Silvestre no Brasil. Brasília: MCT - CNPq e Sociedade Civil Mamirauá, p. 3442,1997.

PIRES, P. S. As dimensões do Ecoturismo. São Paulo, SP: Senac, 2002.

REIGOTA, M. A. Meio Ambiente e Representação Social. São Paulo: Cortez, 1995.

RODRIGUES, R.; BRANCALION, P.; ISERNHAGEN, I. Pacto pela restauração da Mata Atlântica. São Paulo: LERF/ESALQ: Instituto BioAtlântica, 2009. 
SORRENTINO, M. et al. (orgs). Educação Ambiental e Políticas Públicas: Conceitos, Fundamentos e Vivências. 1a. ed. Curitiba: Appris, 2013. v. 1

TOMAZELLO, M. G. C.; FERREIRA, T. R. C. Educação Ambiental: que critérios adotar para avaliar a adequação pedagógica de seus projetos. Ciência \& Educação. Piracicaba, v.7, n.2, 2001.

VENTURIN, N. et al. Sistema Sócio-ecológico, Educação Ambiental e Conservação da natureza. Revista Educação Ambiental em Ação, n. 45, Ano XII, 2013.

VILETA, R. B., RIBEIRO, A.; BATISTA, N. A. Nuvem de palavras como ferramenta de análise de conteúdo: Uma aplicação aos desafios do mestrado profissional em ensino na saúde. Millenium, 2011.

VYGOTSKY, L.S. Psicologia Pedagógica. S.Paulo: Martins Fontes, 2001.

VYGOTSKY, L.S. A Formação Social da Mente. S.Paulo: Martins Fontes, 1998.

WELLS, M.; BRANDON, K. (eds). People and Parks: linking protected areas with local communities. Washington DC: Banco Mundial, WWF, USAID, 1992.

Kelly De Marchi: Universidade Federal de São Carlos, Sorocaba, SP, Brasil. E-mail: kellymarchi@gmail.com

Link para o currículum Lattes http://lattes.cnpq.br/2045017669997920

Ismail Barra Nova de Melo: Universidade Federal de São Carlos, Sorocaba, SP, Brasil.

E-mail: ismail@ufscar.br

Link para o currículum Lattes http://lattes.cnpq.br/3576937472687059

Rita de Cássia Lana: Universidade Federal de São Carlos, Sorocaba, SP, Brasil.

E-mail: lanarc@ufscar.br

Link para o currículum Lattes http://lattes.cnpq.br/1816504631940006

Silvio César Moral Marques: Universidade Federal de São Carlos, Sorocaba, SP, Brasil.

E-mail: silviocmm@ufscar.br

Link para o currículum Lattes http://lattes.cnpq.br/6047434055828372 